\title{
Exploration of Curriculum Reform of Digital Media Art Specialty Under Interdisciplinary Background
}

\author{
Zifei Kong \\ School of Digital Media and Design \\ Neusoft Institute Guangdong \\ Foshan, China \\ kongzifei@nuit.edu.cn
}

\begin{abstract}
The study is aimed to explore whether the curriculum of digital media art major is reasonable and share practical experience for it. Under the background of digital media era, there is a dilemma of the aging curriculum in the training of digital media art talents. Digital media art covers many disciplines and teaching contents, such as digital technology, communication mediums, artistic creation, etc. Faced with such a new interdisciplinary specialty, it is particularly important to explore the curriculum of digital media art major. This paper proposes a series of reform measures for the curriculum of digital media art specialty in Neusoft Institute Guangdong, so as to enhance the market compatibility of digital media art talent training program.
\end{abstract}

Keywords-interdisciplinary; digital media art; curriculum setting

\section{INTRODUCTION}

With the rapid development of science and technology, information technology represented by computers and the Internet has brought tremendous changes to human life. The rapid development of mobile Internet and digital media industry, especially the popularity of smart phones and the emergence of the Internet of Things(IoT), Virtual Reality(VR), Augmented Reality(AR) and Artificial Intelligence(AI), has changed the way of human access to information and knowledge. Digital media is penetrating into all aspects of society, culture and entertainment with an irresistible influence. We are ushering in a new era of mutual integration of art and science. Digital media are carrying unlimited possibilities in the future, and also put forward the demand for fast-growing digital media art-related talents [1]. The target of Digital Media Art Professional Training is to take creativity as the soul, technology as the basis and media as the means. It requires the organic promotion and coordinated development of knowledge and skills among digital media disciplines, and more importantly, the cultivation of talents with interdisciplinary background of arts, engineering and literature.

\section{THE NECESSITY OF INTEGRATION OF DisCIPLINES}

For a long time, higher education in China has always emphasized "subject-centered". Disciplines are separated and specialties are over-refined, resulting in knowledge being isolated, dismembered and box-shaped. The system of students' knowledge composition is relatively single, which makes

This paper is the result of the teaching reform project of Neusoft Institute Guangdong, "Exploring the Reform of Course Setting for Digital Media Art Major under the Interdisciplinary Background". knowledge innovation difficult in the higher education system. Nowadays, the world's scientific and technological problems, social problems and global problems are becoming more and more complex. It is impossible to solve them by relying on the strength of a single discipline. It needs the integration of multidisciplinary knowledge and the collaborative research of multidisciplinary experts [2]. Richard Levin, President of Yale University, once pointed out that two key factors lacking in undergraduate education in China are the cultivation of critical thinking and interdisciplinary extent [3]. Corig Mondy, Microsoft's chief research and strategy officer, believes that the problems facing mankind in the future will become more and more complex. The solution to these problems depends on interdisciplinary cooperation. Business circles especially hope that universities can cultivate more interdisciplinary and cooperative talents [4].

Discipline convergence refers to cross the boundaries of disciplines in Colleges and universities and strengthens the permeability, cross-cutting and innovation among disciplines. Digital media art is an interdisciplinary subject that integrates science, art and humanities, spanning natural sciences, Social Sciences and humanities. As a comprehensive subject, digital media art should build up interdisciplinary and supradisciplinary consciousness and concept in the concept and practice of talent cultivation.

\section{A. Digital technology is the foundation}

"Digital" reflects the scientific and technological foundation of digitalization. It requires that the curriculum system of digital media art should include the basic components of the knowledge system of information technology discipline. Technology is the space and platform of art creation. Students should have a full understanding of basic information technology and digital media technology in order to make their creation suitable for the development of the times.

\section{B. Media is the communication medium}

In the era of "Internet $+"$, the development of media is fast and abundant. From mainstream media to We media, from blogs, micro-blog, WeChat to webcast, and the coming era of virtual reality media, the evolution speed of digital media has greatly exceeded the speed of media renewal in the traditional media era [5]. Media is the carrier of art. The cultivation of digital media artists should pay attention to the grasp of contemporary and future cutting-edge media communication 
Digital media art originates from the intersection and integration of culture, art and technology. In this highly integrated subject of science and technology and artistic creativity, the speed of knowledge change is a severe test for media creators and teaching staff, and creators may lag behind at any time due to the updating of technology [6]. Digital technology and media mediums bring us more space to play in the process of design and creation, but at the same time accompanied by more technical constraints, in addition to requiring practitioners to have exquisite technology, but also to have good artistic literacy and unique personal creativity, both of which are indispensable.

curriculum system of digital media art major in our university is being constructed continuously, dynamically and rigorously in accordance with the actual situation. At present, the major of digital media art mainly carries out teaching in two directions, namely, the course of image creation based on computer technology, which is widely used in digital entertainment industry, and the course of virtual reality technology-based on human-computer interaction, computer graphics and display technology, which is widely used in entertainment, broadcasting, display and education. At the same time, the teaching platform of our major consists of four parts, namely, general course platform, basic course platform, professional course platform and centralized practice platform. Guangzhou Academy of Fine Arts and Guangdong University of Technology. Moreover, in accordance with the principles of differentiated construction and prominent characteristics, the

TABLE I. THE STRUCTURE OF PROFESSIONAL COURSES.

\begin{tabular}{|c|c|c|}
\hline \multicolumn{2}{|c|}{ Course category } & Course title \\
\hline \multirow{4}{*}{\multicolumn{2}{|c|}{ Basic Subject Courses }} & Professional modeling \\
\hline & & Creative thinking \\
\hline & & Formation and Design \\
\hline & & Communication Studies \\
\hline \multirow{12}{*}{\multicolumn{2}{|c|}{ Compulsory Courses for Specialty }} & Professional introduction \\
\hline & & Audio-visual Language \\
\hline & & Sketch \\
\hline & & Digital Image Creative Design \\
\hline & & Photography \\
\hline & & Non-linear Editing \\
\hline & & Special effect synthesis design \\
\hline & & 3-D Foundation \\
\hline & & 3-D Scene Design \\
\hline & & 3-D Animation \\
\hline & & Creative Design of Digital Media \\
\hline & & Digital Media Marketing \\
\hline \multirow{14}{*}{ Selective Course Module for Specialty } & \multirow{7}{*}{ Video effects creation } & Digital Sound Effect Design \\
\hline & & Digital color matching \\
\hline & & Video design \\
\hline & & 3D special effects \\
\hline & & Art of light and shadow \\
\hline & & Application Design of Virtual Reality \\
\hline & & Integrated Image Creation \\
\hline & \multirow{7}{*}{ Interactive Media Design } & UI design \\
\hline & & User Experience and Interaction Design \\
\hline & & Web Design \\
\hline & & New Media Display Design \\
\hline & & Digital Game Design Foundation \\
\hline & & \begin{tabular}{|c|} 
Virtual Reality Technology \\
\end{tabular} \\
\hline & & Comprehensive Creation of Virtual Reality \\
\hline
\end{tabular}

\section{B. Strengthening the Construction of Professional Teachers}

As an interdisciplinary subject, digital media art specialty not only requires students to study, think and create interdisciplinary, but also requires talents with complex and interdisciplinary backgrounds in the construction of teaching team, so as to improve the knowledge structure of teachers, lay 
a solid foundation for teaching effect, and promote the further development of teaching reform. Therefore, in the construction of teachers' team, we should speed up the introduction of highlevel applied talents. On the one hand, young teachers with background or practical experience in new media and digital media industries are introduced into the teaching system of colleges and universities, bringing new demands, new technologies, new concepts and new markets into the profession. At the same time, the practical advantages of "double-qualified" teachers are utilized to promote professional development.

TABLE II. THE SUBJECT BACKGROUND STATISTICS OF FULL-TIME DIGITAL MEDIA ART TEACHERS IN NEUSOFT INSTITUTE GUANGDONG.

\begin{tabular}{|c|c|}
\hline Discipline background & Number \\
\hline Fine Arts & 2 \\
\hline Journalism and Communication & 1 \\
\hline Drama and Film and Television Science & 1 \\
\hline Cinematography & 1 \\
\hline Computer Application Technology & 1 \\
\hline Educational Technology & 2 \\
\hline
\end{tabular}

\section{Innovative Practice Teaching Model}

As a specialty with strong integration of disciplines, digital media art practice teaching occupies a large proportion of the whole teaching system. Through continuous improvement, the current practice teaching of digital media art specialty has formed a relatively complete system. At present, the proportion of theoretical and practical hours of the compulsory course is $4: 1$, the proportion of theoretical and practical hours of the compulsory course is $1: 2.2$, and the proportion of theoretical and practical hours of the optional course is $4.4: 1$. In addition, we have a total of 520 hours of concentrated practice, which includes three practice semesters. The total proportion of practice teaching in digital media art major is 37\%.

In addition, there are many professional laboratories supporting the practical teaching platform of digital media art specialty. At present, there are digital audio recording room, virtual studio, photographic camera laboratory, virtual reality laboratory, CG laboratory, visual creativity laboratory and so on. At the same time, our school has established a number of teachers studios, Sovo College as the practice teaching base in the school, and has a relatively stable practice teaching base outside the school. Furthermore, relying on the school practice semester system, introducing school-enterprise cooperation projects and external assessment mechanism, we can use the requirements which close to the real market to test the effect of teacher teaching and student course achievement.

Drawing on the advanced experience of other universities and combining with the actual situation of our university, we have the following specific measures to cultivate the practical ability of digital media art specialty:

1) Project-based curriculum content: In terms of curriculum structure and teaching content, we should give priority to application, strengthen the combination of theory and practice, pay attention to the practicality of teaching process, introduce real topics to strengthen the practical connotation of teaching process, adopt project-based classroom work to promote teaching, and emphasize teaching strategies and methods characterized by "inquiry". Especially in some backbone courses with practical part, some comprehensive creative assignments are set up. Such a project-based practice mode is conducive to strengthening students' application and innovation ability. Whether in the form of individual or team, in the process of completing the project, students can choose more specific professional direction according to their own personal hobbies and development vision, which on the one hand reflects the different professional focus of creative members; on the other hand, it also improves the comprehensive factors of their own creation quality.

2) Introducing external assessment mechanism into practice semester: Neusoft Institute Guangdong is a college aiming at cultivating applied talents. It adopts the "1321" model, that is, there are two theoretical and one practical semester in a year. It carries out project practice in the practical semester to effectively cultivate students' practical and innovative abilities. According to the talent training plan of digital media art specialty, we set up different practice projects for students of different grades. The teaching idea of "Projectdriven, team-work, each director takes his lead" runs through the practice projects. We try our best to let each student find their own position in the team, exert their strengths, cultivate team consciousness, and lay a foundation for future employment. The proposition and assessment part of the practical semester assessment project are independently responsible by the external assessment experts, and the fulltime curriculum teachers are responsible for guiding students to complete. On the one hand, this mechanism can understand the demand and direction of the market through actual projects, on the other hand, it can also reflect the teaching effect of teachers from students' achievements.

3) Encouraging students to participate in comprehensive competitions: Develop various forms of professional development activities, and encourage students to actively participate in high-level, comprehensive film and television, interactive and graphic creative competitions, with high-quality products as demonstrations, with results to drive development, cultivate students' independent innovation ability, apply the theoretical knowledge learned in the class to the creative process, but also increase contacts with society, as well as the ability of interpersonal communication and teamwork.

\section{SUMMARY}

Digital media art is a combination of "science and technology", "communication" and "art", but it is not only a simple superposition of the three but also a deep, multidimensional and cross-disciplinary integration. Nowadays, the problems of human society are becoming more and more complicated. Many social problems can't be solved by a single discipline. The traditional training mode of talents in colleges and universities has been unable to meet the future development of human beings. The rise and change of the digital media industry haVE led to AN increasingly clear demand for professionals in the industry, thus continuously affecting the construction of digital media art professionals training programs. As a sunrise specialty with great characteristics, digital media art specialty needs to grasp the opportunity to cultivate high-quality application-oriented 
compound talents under the background of discipline integration, provide innovative impetus for socialist development, and respond to the call of the era of media integration.

\section{REFERENCES}

[1] H.Zhang, "The Training Practice of Digital Media Art Talent in University under the Background of Internet”, Idea \& Design, vol. 06, pp. 67-72, November 2017.(In Chinese)

[2] J.M.Li, "Transformation of Higher Education in Interdisciplinary Perspective”, Jianghai Academic Journal, vol. 06, pp. 228-233+239, November 2012.(In Chinese)
[3] M. Franklin(translated by the Central Institute of Educational Science), "The Power of Change - Perspective of Educational Change", Beijing: Educational Science Press, 2004.

[4] J.T.Klein (translated by Z. Jiang), "Transboundary: Knowledge, Discipline, Interdisciplinary”, Nanjing: Nanjing University Press, 2005.

[5] Y.Hu, "Discussing the interdisciplinary characteristics in the training of digital media art talents", Art Education, vol. 04, pp.11, February 2018.(In Chinese)

[6] Z.F.Ma, "On the Education Model of Innovative and Digital Media Art Talents”, Press Circles, vol. 03, pp.166-167+170, June 2010.(In Chinese) 